\title{
Experiment Research on Bonding Effect of Poly(lactic-co-glycolic acid) Device by Surface Treatment Method
}

\author{
Xiaopeng Wang, ${ }^{1}$ Kun Lian, ${ }^{2}$ and Tianning Chen ${ }^{1}$ \\ ${ }^{1}$ School of Mechanical Engineering, State Key Laboratory for Strength and Vibration of Mechanical Structures, \\ Xian Jiaotong University, Xian 710049, China \\ ${ }^{2}$ School of Nano-Science and Nano-Engineering (Suzhou), Collaborative Innovation Center of Suzhou Nano Science and Technology, \\ Xian Jiaotong University, Xian 710049, China \\ Correspondence should be addressed to Xiaopeng Wang; xpwang@mail.xjtu.edu.cn
}

Received 4 September 2014; Accepted 21 December 2014

Academic Editor: Long Yu

Copyright (C) 2015 Xiaopeng Wang et al. This is an open access article distributed under the Creative Commons Attribution License, which permits unrestricted use, distribution, and reproduction in any medium, provided the original work is properly cited.

\begin{abstract}
According to the low temperature and high effective bonding problem of microdevices made of degradable polymer PLGA, chemical, plasma, and UV irradiation method are used to study the experimental surface treatment of PLGA films and microdevices bonding process. The results show that all three methods can reduce the surface contact angle of PLGA films, the contact angle increases with time at room temperature, and the PLGA films contact angle is almost unchanged under refrigeration. The PLGA film bonding temperature is significantly reduced after UV irradiation, and the bonding interfaces also generate diffusion cross linking layer are dense and uniform.
\end{abstract}

\section{Introduction}

Copolymer poly(lactic-co-glycolic acid) (PLGA) is formed by the polymerization of lactic acid and glycolic acid, and it has many advantages, for example, excellent biocompatibility, biodegradability, lack of toxicity, and good thermoplasticity. PLGA has been approved to be used in pharmaceutical products or medical devices by the United States Food and Drug Administration (US FDA) and is widely used in pharmaceutical, medical engineering, and the modern industrial field [1-4]. Compared to traditional oral and injection drug delivery, the multicavity implantable controlledrelease drug delivery system (MIDDS) made of PLGA can relieve the suffering of the patients and improve the treatment effect dramatically because of its targeted releasing, rate controlling, large amount drug delivering, and long period releasing [5-7]. Shown in Figure 1, the micro MIDDS made of PLGA with only $200 \mu \mathrm{m}$ minimum structure width is combined by bonding PLGA microstructures and films, and the parts are both fabricated by MEMS technologies. Thus the bonding quality between the microstructure and the film is the key factor to achieve MIDDS predefined functions. If the macromolecular drugs are filled into MIDDS, such as polypeptides and enzymes, because the losing activity temperature of the drug is usually between 40 and $70^{\circ} \mathrm{C}$, high adhesive bonding or joining techniques cannot be employed. Therefore, drug delivery systems for PLGA micro-bonding technology to connect low temperature needs to be studied.

According to polymer bonding theory, the bonding process is divided into two steps: adsorption and diffusion. Polymer interface needs to have good adsorption capacity, in order to protect the well-bonded prerequisite. Interface adsorption performance is directly related to its surface free energy: the surface free energy increases in correlation with the adsorption capacity of the interface. Many scholars have studied the polymethyl methacrylate (PMMA) bonding process after surface treatment of polymer; there are also some studies about PLGA material surface treatment processes. For example, after surface treatment of the PMMA and the resin (COC) sample by UV/ozone irradiation, Tsao and his colleagues obtained bonding results of the PMMA and COC substrate by thermocompression bonding process at lower 


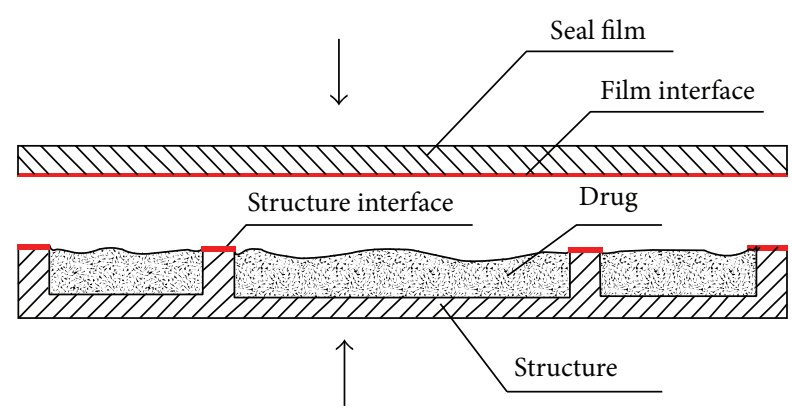

Figure 1: Schematic design of biodegradable microstructure for drug delivery system.

temperatures [8]. Khorasani and his colleagues performed surface treatment of PLLA and PLGA samples in an oxygen atmosphere using radio frequency (RF) plasma technology, and it was found that the process can greatly improve the surface energy of the polymer material [9]. Inagaki and his colleagues did surface modification of PLA film surface by Ar-plasma, and they found the Ar-plasma treatment did not lead to hydrophilic modification of the PLA film surface [10]. At $20 \mathrm{~Pa}$ oxygen atmosphere and $50 \mathrm{~W}, 13.56 \mathrm{MHz}$ glow discharge conditions, Shen made a PLGA material plasma treatment that enhanced the success rate of PLGA grafted with collagen and improved the PLGA compatibility in vivo ultimately [11]. Jacobs and his colleagues used the medium pressure plasma treatment of PLA to investigate its surface modification, and water contact angle measurements showed an increased hydrophilic character of the foil surface after plasma treatment [12]. De Geyter and his colleagues employed dielectric barrier discharge operating in different atmospheres (air, nitrogen, helium and argon) and at medium pressure to modify the surface properties of PLA, the results showed that the discharge gas can have a significant influence on the chemical composition of the PLA surfaces [13]. Other researchers did many works about PLGA/PLA surface treatment or modification, and they found the biocompatibility and thermal stability improvement or mechanical properties changes [14-23].

In this research, the highly efficient and low temperature thermocompression bonding process is proposed by increasing the surface energy of PLGA. Chemical, plasma, and UV irradiation methods are used to modify the surface character of PLGA films, which aims to improve the face energy and surface hydrophilicity, lower the bonding temperature and processing conditions, and optimize the bonding strength and interface morphology.

\section{Experimental Methods}

Poly(lactide-co-glycolide) (PLGA) was purchased from Lactel International Absorbable Polymers (Pelham, AL, USA), with lactide: glycolide $=50: 50$, inherent viscosity range: $0.55-0.75 \mathrm{dL} / \mathrm{g}$, specific gravity: $1.34 \mathrm{~g} / \mathrm{ml}$, modulus: $2 \times$ $10^{5} \mathrm{psi}-4 \times 10^{5} \mathrm{psi}$, and amorphous melting point and glass transition temperature: $40-50^{\circ} \mathrm{C}$. The granular PLGA materials are embossed to $400 \mu \mathrm{m}$ films at $70^{\circ} \mathrm{C}$ using a selfmade hot embossing machine.

The most convenient method to assess the treatment effects is to measure the contact angle. Since the material has a small surface contact angle, it also has a higher surface free energy and an improved surface hydrophilicity. This surface contact angle is measured using deionized water as the reference fluid.

2.1. Chemical Treatment. PLGA films are separated into 7 groups, with 5 films for each, immersed in $2 \% \mathrm{NaOH}$ solution for surface hydrolysis for $0 \mathrm{~min}, 5 \mathrm{~min}, 10 \mathrm{~min}, 20 \mathrm{~min}$, $40 \mathrm{~min}, 60 \mathrm{~min}$, and $80 \mathrm{~min}$, respectively, and then washed by deionized water. Their surface contact angles are measured using a contact angle instrument after drying in fluid nitrogen at room temperature.

2.2. Plasma Treatments. The Plasma-Enhanced CVD system produced by Japan SANKEN is used in plasma treatment at the power of $50 \mathrm{~W}$ and vacuum degree of $20 \mathrm{~Pa}$, with the oxygen as the reactive gas. The processes are as follows: PLGA films are placed beneath the electrode in the cavity; the vacuum degree is reduced to $10 \mathrm{~Pa}$ and then maintained at $20 \mathrm{~Pa}$ after filling with oxygen. The glow discharge plasma treatment could be proceeding between two electrodes by enabling the $50 \mathrm{~W}$ power, $13.56 \mathrm{MHz}$ alternating current according to the predetermined time. For another $10 \mathrm{~min}$, the films are taken out for measurement.

2.3. UV Irradiation Treatment. $126 \mathrm{~nm}$ and $172 \mathrm{~nm}$ UV are used to handle PLGA films, and the excimer UV lamp is provided by China Jiangsu Youwei Optoelectronics Co., Ltd. Irradiation light is $70 \mathrm{~W}$, boot time $<1 \mathrm{~s}$, illuminated object temperature $<40^{\circ} \mathrm{C}$, and AC power is $220 \mathrm{~V} / 50 \mathrm{~Hz}$. In the experiment, PLGA films are placed below the excimer UV lamp first, then after completing predetermined time irradiation the films are removed for measurement.

2.4. Measurement and Assessment. Contact angle measurement: Contact Angle Meter (Type OCA20) produced by Germany Dataphysics is used to measure the contact angle by sessile drop method and deionized water as the reference solution. The results are recorded by the equipment automatically.

Bonding strength measurement: the tension test is performed by America Electron-Tensile Tester (Type 1095), and the tensile rate is $1 \mathrm{~mm} / \mathrm{min}$.

Interface morphology measurement: the films are observed by Japan Olympus microscope (Type SZX16).

\section{Results and Discussion}

3.1. Chemical Treatment Result. Figure 2 shows the chemical treatment results of the PLGA film. Where, $x$-axis represents time of chemical treatment, $y$-axis represents the value of the contact angle. From the figure we can see that $\mathrm{NaOH}$ treatment reduces the surface contact angle of the PLGA film, 


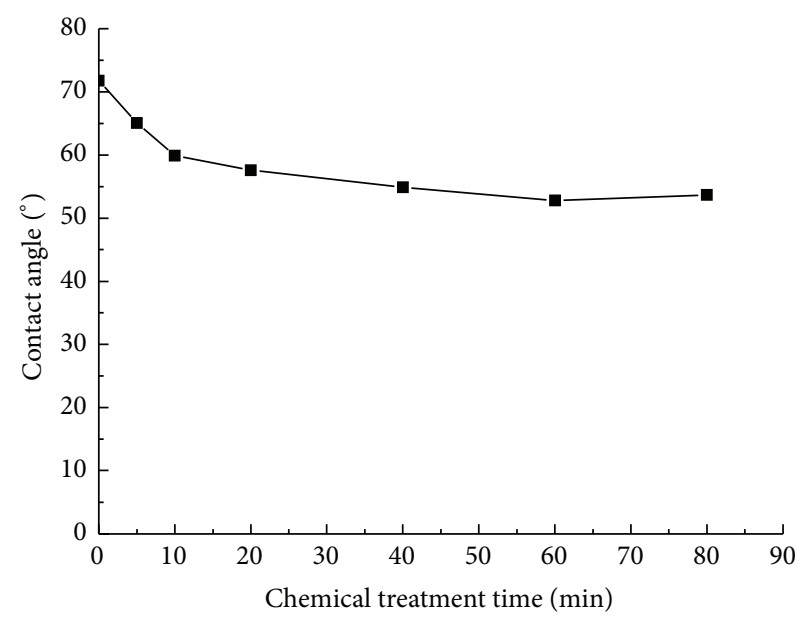

Figure 2: Contact angle curve of PLGA films after chemical treatment.

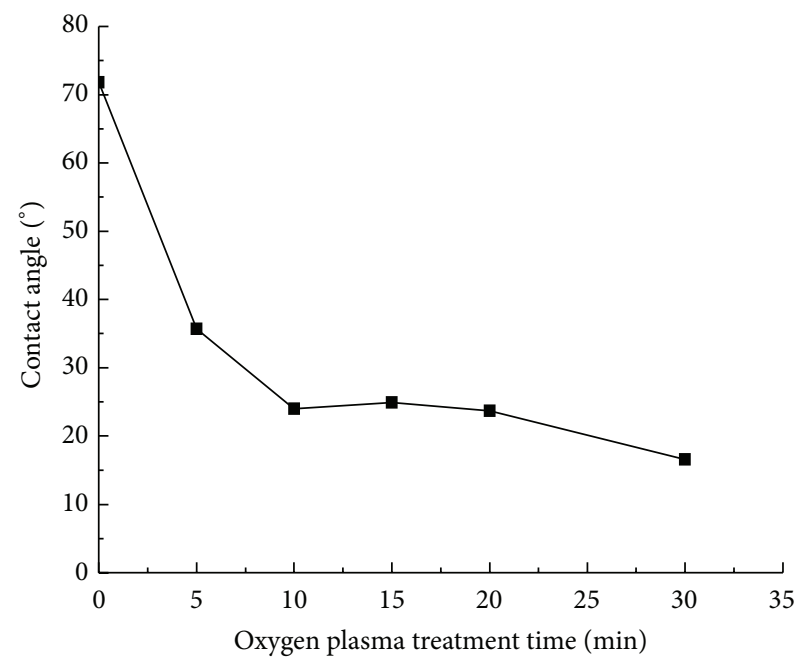

FIGURE 3: Contact angle curve of PLGA films after plasma treatment.

and PLGA film surface contact angle drops from $70^{\circ}$ to $52^{\circ}$ after 60 minutes.

3.2. Plasma Treatment Result. Figure 3 shows the Plasma treatment results of the PLGA film, where the $x$-axis represents time of plasma treatment and the $y$-axis represents the value of the contact angle. From the figure we can observe the following: plasma treatment reduces the surface contact angle of the PLGA film; PLGA film surface contact angle drops from $70^{\circ}$ to $35^{\circ}$ after 5 minutes; PLGA film surface contact angle drops from $70^{\circ}$ to $25^{\circ}$ after 10 minutes; PLGA film contact angle decreases to $15^{\circ}$ after 30 minutes. The Figure 3 is similar to [13] results, and [13] employed the oxygen plasma treated PLGA film.

3.3. UV Irradiation Treatment Result. Figure 4 shows two kinds of UV irradiation treatment results of the PLGA film. Where the $x$-axis represents time of UV irradiation

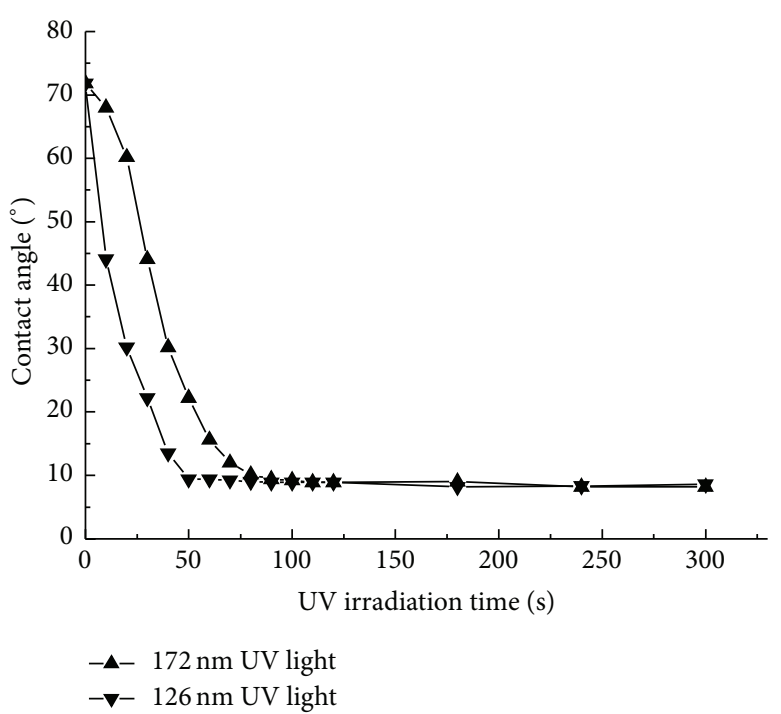

FIGURE 4: Contact angle curves of PLGA films after two kinds of UV irradiation treatment.

treatment; $y$-axis represents the value of the contact angle; A symbol represents the result of $172 \mathrm{~nm}$ excimer ultraviolet light irradiation; $\boldsymbol{\nabla}$ symbol represents the result of $126 \mathrm{~nm}$ excimer UV ligh irradiation. From the figure we can observe the following: UV irradiation treatment reduces the surface contact angle of the PLGA film; PLGA film surface contact angle drops from $70^{\circ}$ to $10^{\circ}$ after about 50 seconds; PLGA film contact angle change curves after $126 \mathrm{~nm}$ and $172 \mathrm{~nm}$ excimer ultraviolet radiation have similar rules.

3.4. The Ageing Effect of Surface Treatment Result. The longchain molecules of the polymer surface are broken into short-chain molecules after plasma and UV treatment, which produce many hydrophilic groups increasing the surface hydrophilicity, surface energy, and adhesiveness. But this effect may fade away over time due to its instability, which is called the ageing effect of surface treatment. In order to investigate the ageing effect of PLGA surface treatment, the specimens after plasma and UV irradiation treatment are placed in room temperature $\left(20-25^{\circ} \mathrm{C}\right)$ and refrigerator temperature $\left(4-6^{\circ} \mathrm{C}\right)$, respectively; the storage humidity is about $40 \%$, and the contact angle curves are obtained. Thus, the ageing effect of different treatments is obtained, and the influence of temperature on ageing is also a preliminary understanding.

Figure 5 shows contact angle ageing results of PLGA film after two kinds of surface treatment, where the $x$-axis represents the keep time after two kinds of surface treatment; $y$-axis represents the value of the contact angle; symbol represents the contact angle kept at room temperature after plasma treatment; $\square$ symbol represents the contact angle kept at room temperature after UV irradiation; $\boldsymbol{\nabla}$ symbol represents the contact angle kept at freezer temperature after plasma treatment; $\nabla$ symbol represents the contact angle kept at freezer temperature after UV irradiation. From the figure we can analyze the following conclusions. 


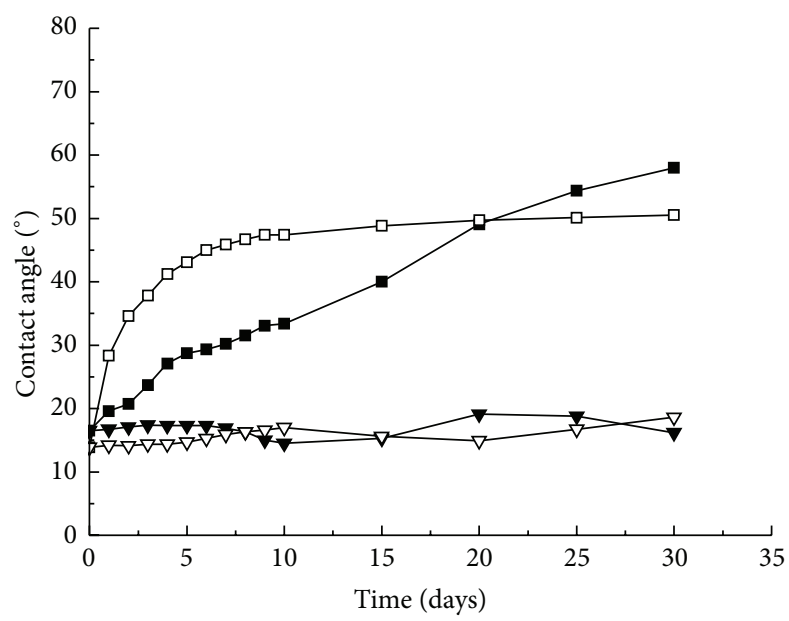

$\rightarrow$ Kept in room temperature after plasma treatment

$\rightarrow-$ Kept in room temperature after UV irradiation

$\neg-$ Kept in freezer after plasma treatment

$\rightarrow-$ Kept in freezer after UV irradiation

FIGURE 5: Contact angle ageing curve of PLGA films after treatment.

At room temperature, the two kinds of the surface-treated PLGA film surface contact angle continuously increase with time. The reason for this result is that PLGA film surface has a large number of polar groups after treatment, which results in the film surface retaining high energy and becomes very unstable state. The substance of the energy is lower when the system is more stable, so the PLGA film surface contact angle increases. It will reduce the energy to the lowest point, in order to maintain the stability of the system.

At room temperature, the contact angle of PLGA film after the UV irradiation treatment changes quickly: the contact angle increases to 2 times the original after 1 day, increases to 3 times the original after 3 days, and subsequently increases to 5 times the original after 6 days. But, at the same room temperature, the contact angle of PLGA film linearly increases only 1 time after 10 days. It is mainly due to: the ultraviolet irradiation mechanism is that PLGA long chain is interrupted by high energy photon and becomes short chain; during storage at room temperature, short-chain dynamics regroup which results in the PLGA film surface contact angle increase. However, the contact angle of PLGA film after plasma treatment change, not only have a short chain, but the air particles are ionized oxygen, nitrogen, and the surface of particles and the like polar groups react, polar surface groups turn inward resulting aging resistance. After plasma treatment, the surface of the PLGA film not only has short chain, but also has polar groups that react by ionized oxygen, nitrogen, and the particles of surface. Material surface polar groups turn inward causing ageing effect. Therefore these two approaches obtained different change rates of contact angle. From the data, the polar group turning inward is slower than the dynamic reorganization of the molecular chain; it also can be obtained from Figure 5, relative to the total change, that the contact angle change is not large at room temperature within 1 day. The contact angles changed little when kept in the freezer,

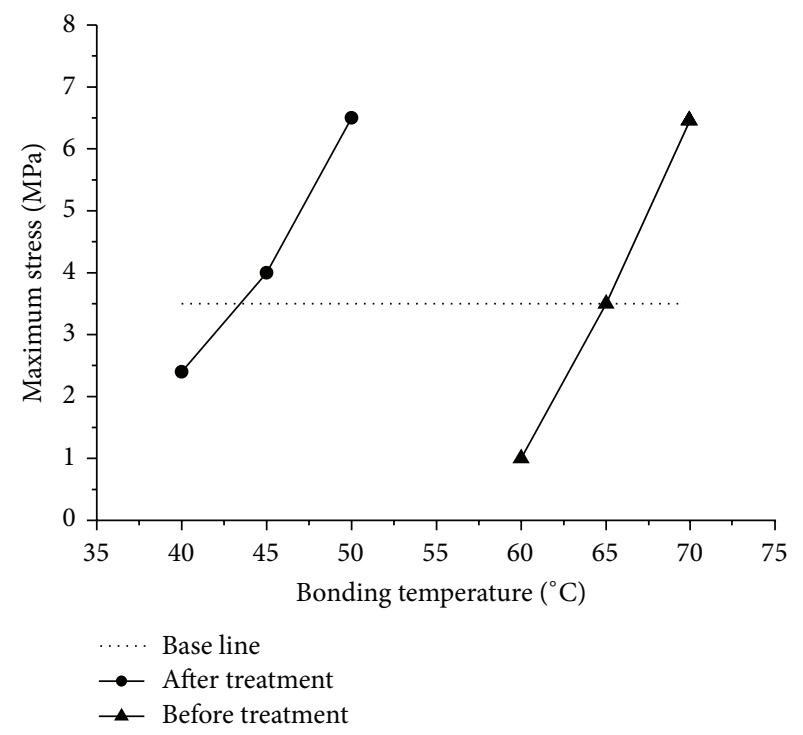

FIGURE 6: Bonding strength and temperature comparison chart.

which shows that the low temperature environment is a good way to preserve the films to be bonded. The degradation property of polymers may also vary due to the long-chains being broken. But short term surface treatment will not influence the overall degradation performance due to the bulk degradation character of PLGA.

Compared to the literatures study, there are also some results similar to ours. For example, Prasertsung and his colleagues did the similar research with this paper, and they studied the water contact angle of oxygen plasmatreated PLGA films after ageing at different ageing times and temperatures. They found that the films aged at high storage temperature $\left(20^{\circ} \mathrm{C}, 50^{\circ} \mathrm{C}\right)$ exhibited a faster recovery of contact angle compared to that at low storage temperature $\left(5^{\circ} \mathrm{C}\right)[24]$.

3.5. Effects on Bonding Temperature. The ultimate goal of PLGA surface treatment is to improve bonding properties and promote how different PLGA-based structures connected together well at the low temperature. The relationships between bonding temperatures and bonding strength are studied to show the effects of UV irradiation treatment. The experimental films are also irradiated under $126 \mathrm{~nm}$ UV of $70 \mathrm{~W}$ UV light for $45 \mathrm{~s}$ and then bonding at pressure $4 \mathrm{~N}$ and time $45 \mathrm{~s}$ in different temperatures. The bonding strength is tested according to the method of experiment. The ones without treatment are used as the control.

Figure 6 shows bonding strength and temperature comparison chart of the PLGA film. Where $x$-axis represents the bonding temperature; $y$-axis represents the tensile breaking strength of the bonding; base line means the minimum strength value required to achieve bonding; $\downarrow$ symbol represents the tensile breaking strength after surface treatment; A symbol represents the tensile breaking strength without surface treatment. From this figure we can obtain the following conclusions: when reaching the same bonding strength, 


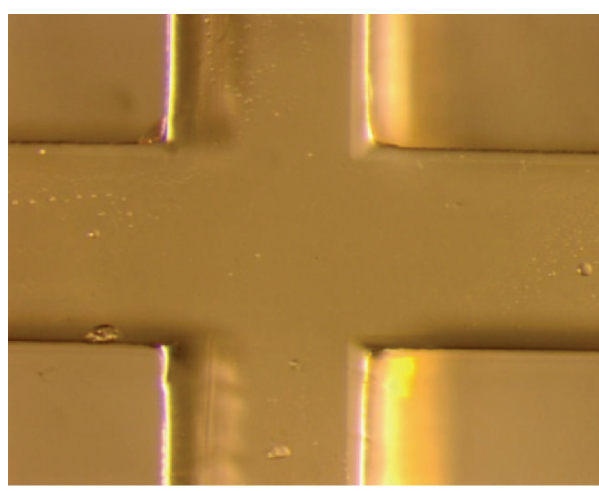

(a)

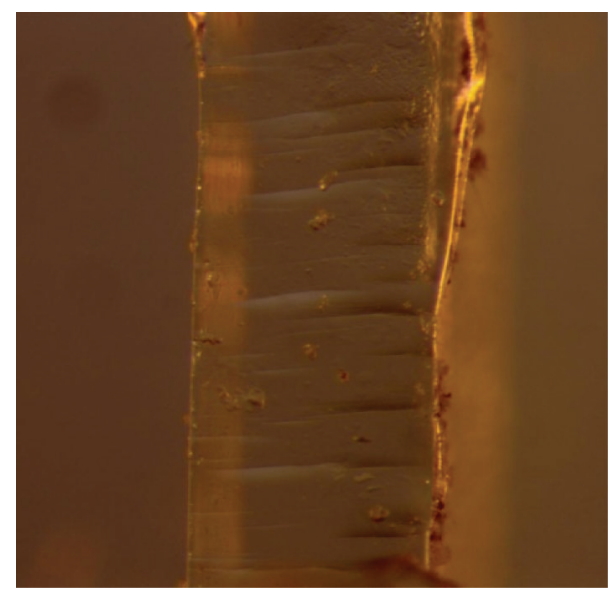

(b1)

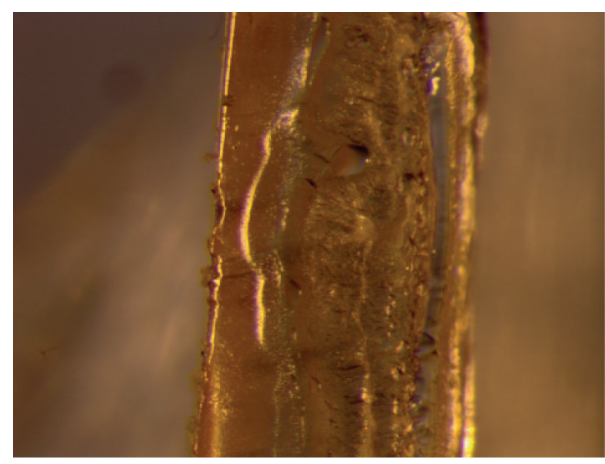

(c1)

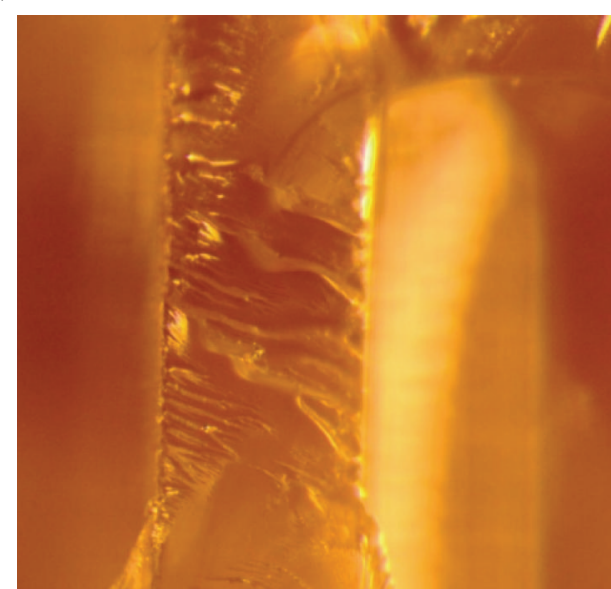

(b2)

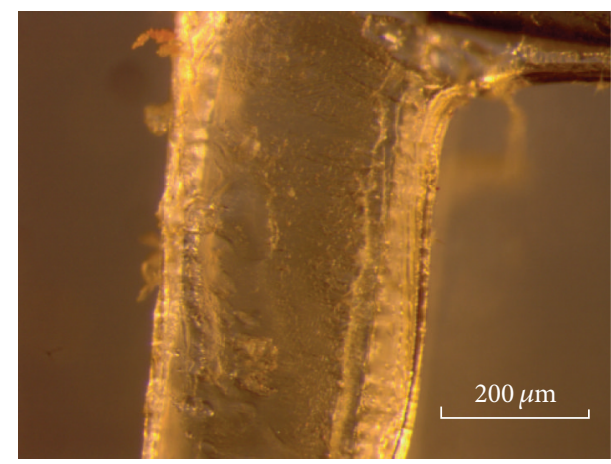

(c2)

FIGURE 7: Interface morphology photographs of bonding effect $\times 20$ ((a) microstructure interface before bonding; (b1) tearing interface 1 without treatment at $65^{\circ} \mathrm{C}$; (b2) tearing tnterface 2 without treatment at $65^{\circ} \mathrm{C}$; (c1) tearing interface 1 after treatment at $45^{\circ} \mathrm{C}$; (c2) tearing interface 2 after treatment at $45^{\circ} \mathrm{C}$ ).

the bonding temperature after treatment is $20^{\circ} \mathrm{C}$ lower than without treatment; and the satisfying bonding strength which surpasses the base line is obtained at about $45^{\circ} \mathrm{C}$. This shows that the bonding temperature is truly lowered by surface treatment and modification.

3.6. Changes of Interface Morphology. After being removed off the new structure by bonding, the morphology of the bonding interface is a good indication of the bonding effect. When the tear interface is relatively smooth, this indicates that it do not produce an effective bonding. When the tear interface is very rough, with lots of ravines and glitches, then the bond is effective. Figure 7 is enlarged 20 times showing the effects of PLGA microstructure interface morphology photographs of bonding, where (a) is microstructure interface morphology photograph before bonding; (b1) is tearing interface 1 morphology photograph without treatment bonding at $65^{\circ} \mathrm{C}$; (b2) is tearing interface 2 morphology photograph without treatment bonding at $65^{\circ} \mathrm{C} ;(\mathrm{cl})$ is tearing interface 1 morphology photograph after UV treatment bonding at $45^{\circ} \mathrm{C}$; 
(c2) is tearing interface 2 morphology photograph after UV treatment bonding at $45^{\circ} \mathrm{C}$.

From Figure 7, we can obtain the following results: Prior to bonding, PLGA has smooth interface; after bonding, the tear PLGA presents many broken gullies and different interfaces; in the thermo compression bonding process, the bonding interface does occur the molecular adsorption, diffusion and crosslinking. The maximum stress of tearing before treatment at $65^{\circ} \mathrm{C}$ and ones after UV treatment at $45^{\circ} \mathrm{C}$ are nearly the same (Figure 6). But the ravines and burrs of UV treatment (Figures 7(b1) and 7(b2)) are much denser and uniformly distributed compared to the ones without treatment (Figures $7(\mathrm{cl})$ and $7(\mathrm{c} 2)$ ). This phenomenon coincides with the surface long-chains being broken by UV irradiation. In summation, the UV irradiation for PLGA films will not only lessen the bonding process requirements, but also optimize the bonding interface to create a dense and uniformly diffusive layer.

\section{Conclusions}

Chemical, plasma, and UV irradiation treatments can reduce the surface contact angle of PLGA, and the latter is better. After processing of the ion and the ultraviolet irradiation, PLGA film surface contact angle increases with time at room temperature, but the change is little within one day. Refrigeration preserved PLGA film surface contact angle changes a little. If the material bonding operation cannot be carried out immediately after surface treatment, it should be kept in a low temperature environment. The PLGA film surface after UV irradiation can reach ideal hot bonding strength at about $45^{\circ} \mathrm{C}$, and UV irradiation treatment process significantly reduces the temperature of the bonding. PLGA film after the UV irradiation treatment can not only reduce the microstructure of the thermo compression bonding process condition, but also be able to optimize the morphology of the coupling interface. In addition, the process can generate a uniform and dense layer as possible diffusion of cross-linking coupling layer between the bonding interfaces.

\section{Conflict of Interests}

The authors declare that there is no conflict of interests regarding the publication of this paper.

\section{Acknowledgments}

This work is supported by Natural Science Foundation of China (no. 50705074), Collaborative Innovation Center of Suzhou Nano Science and Technology, and Fundamental Research Funds for the Central Universities.

\section{References}

[1] D. Garlotta, "A literature review of poly(lactic acid)," Journal of Polymers and the Environment, vol. 9, no. 2, pp. 63-84, 2001.

[2] E. Vey, C. Roger, L. Meehan et al., "Degradation mechanism of poly(lactic-co-glycolic) acid block copolymer cast films in phosphate buffer solution," Polymer Degradation and Stability, vol. 93, no. 10, pp. 1869-1876, 2008.

[3] C. Gao, H. Ma, X. Liu et al., "Effects of thermal treatment on the microstructure and thermal and mechanical properties of poly(lactic acid) fibers," Polymer Engineering and Science, vol. 53, no. 5, pp. 976-981, 2013.

[4] J. M. Chan, L. Zhang, K. P. Yuet et al., "PLGA-lecithin-PEG coreshell nanoparticles for controlled drug delivery," Biomaterials, vol. 30, no. 8, pp. 1627-1634, 2009.

[5] H. K. Makadia and S. J. Siegel, "Poly Lactic-co-Glycolic Acid (PLGA) as biodegradable controlled drug delivery carrier," Polymers, vol. 3, no. 3, pp. 1377-1397, 2011.

[6] X. P. Wang, T. N. Chen, and Z. X. Yang, "Modeling and simulation of drug delivery from a new type of biodegradable polymer micro-device," Sensors and Actuators A: Physical, vol. 133, no. 2, pp. 363-367, 2007.

[7] Y. Gao, T. Chen, and X. Wang, "Numerical modeling of a novel degradable drug delivery system with microholes," Microsystem Technologies, vol. 17, no. 3, pp. 387-394, 2011.

[8] C. W. Tsao, L. Hromada, J. Liu, P. Kumar, and D. L. DeVoe, "Low temperature bonding of PMMA and COC microfluidic substrates using UV/ozone surface treatment," Lab on a Chip, vol. 7, no. 4, pp. 499-505, 2007.

[9] M. T. Khorasani, H. Mirzadeh, and S. Irani, "Plasma surface modification of poly (L-lactic acid) and poly (lactic-co-glycolic acid) films for improvement of nerve cells adhesion," Radiation Physics and Chemistry, vol. 77, no. 3, pp. 280-287, 2008.

[10] N. Inagaki, K. Narushima, Y. Tsutsui, and Y. Ohyama, "Surface modification and degradation of poly(lactic acid) films by Arplasma," Journal of Adhesion Science and Technology, vol. 16, no. 8, pp. 1041-1054, 2002.

[11] H. Shen, X. Hu, F. Yang, J. Bei, and S. Wang, "Combining oxygen plasma treatment with anchorage of cationized gelatin for enhancing cell affinity of poly(lactide-co-glycolide)," Biomaterials, vol. 28, no. 29, pp. 4219-4230, 2007.

[12] T. Jacobs, H. Declercq, N. De Geyter et al., "Plasma surface modification of polylactic acid to promote interaction with fibroblasts," Journal of Materials Science: Materials in Medicine, vol. 24, no. 2, pp. 469-478, 2013.

[13] N. De Geyter, R. Morent, T. Desmet et al., "Plasma modification of polylactic acid in a medium pressure DBD," Surface and Coatings Technology, vol. 204, no. 20, pp. 3272-3279, 2010.

[14] Z. Karahaliloğlu, B. Ercan, S. Chung, E. Taylor, E. B. Denkbaş, and T. J. Webster, "Nanostructured anti-bacterial poly-lacticco-glycolic acid films for skin tissue engineering applications," Journal of Biomedical Materials Research. Part A, vol. 102, no. 12, pp. 4598-4608, 2014.

[15] É. Kiss, E. Kutnyánszky, and I. Bertóti, "Modification of poly(lactic/glycolic acid) surface by chemical attachment of polyethylene glycol," Langmuir, vol. 26, no. 3, pp. 1440-1444, 2010.

[16] Y.-C. Huang, C.-C. Huang, Y.-Y. Huang, and K.-S. Chen, "Surface modification and characterization of chitosan or PLGA membrane with laminin by chemical and oxygen plasma treatment for neural regeneration," Journal of Biomedical Materials Research Part A, vol. 82, no. 4, pp. 842-851, 2007.

[17] S. Yoshida, K. Hagiwara, T. Hasebe, and A. Hotta, "Surface modification of polymers by plasma treatments for the enhancement of biocompatibility and controlled drug release," Surface and Coatings Technology, vol. 233, pp. 99-107, 2013. 
[18] Y. Wang, P. Li, and L. Kong, "Chitosan-modified PLGA nanoparticles with versatile surface for improved drug delivery," AAPS PharmSciTech, vol. 14, no. 2, pp. 585-592, 2013.

[19] F. Sarasini, D. Puglia, E. Fortunati, J. M. Kenny, and C. Santulli, "Effect of fiber surface treatments on thermo-mechanical behavior of poly(lactic acid)/phormium tenax composites," Journal of Polymers and the Environment, vol. 21, no. 3, pp. 881891, 2013.

[20] Z. W. Xie, G. Buschle-Diller, P. Deinnocentes, and R. C. Bird, "Electrospun poly(D,L)-lactide nonwoven mats for biomedical application: surface area shrinkage and surface entrapment," Journal of Applied Polymer Science, vol. 122, no. 2, pp. 1219-1225, 2011.

[21] B. Asaithambi, G. Ganesan, and S. Ananda Kumar, "Biocomposites: development and mechanical characterization of banana/sisal fibre reinforced poly lactic acid (PLA) hybrid composites," Fibers and Polymers, vol. 15, no. 4, pp. 847-854, 2014.

[22] N. Zhou, B. Yu, J. Sun, L. Yao, and Y. Qiu, "Influence of chemical treatments on the interfacial properties of ramie fiber reinforced poly(lactic acid) (pla) composites," Journal of Biobased Materials and Bioenergy, vol. 6, no. 5, pp. 564-568, 2012.

[23] D. Kurniawan, B. S. Kim, H. Y. Lee, and J. Y. Lim, "Atmospheric pressure glow discharge plasma polymerization for surface treatment on sized basalt fiber/polylactic acid composites," Composites Part B: Engineering, vol. 43, no. 3, pp. 1010-1014, 2012.

[24] I. Prasertsung, R. Mongkolnavin, S. Damrongsakkul, and C. S. Wong, "Surface modification of dehydrothermal crosslinked gelatin film using a $50 \mathrm{~Hz}$ oxygen glow discharge," Surface and Coatings Technology, vol. 205, supplement 1, pp. S133-S138, 2010. 

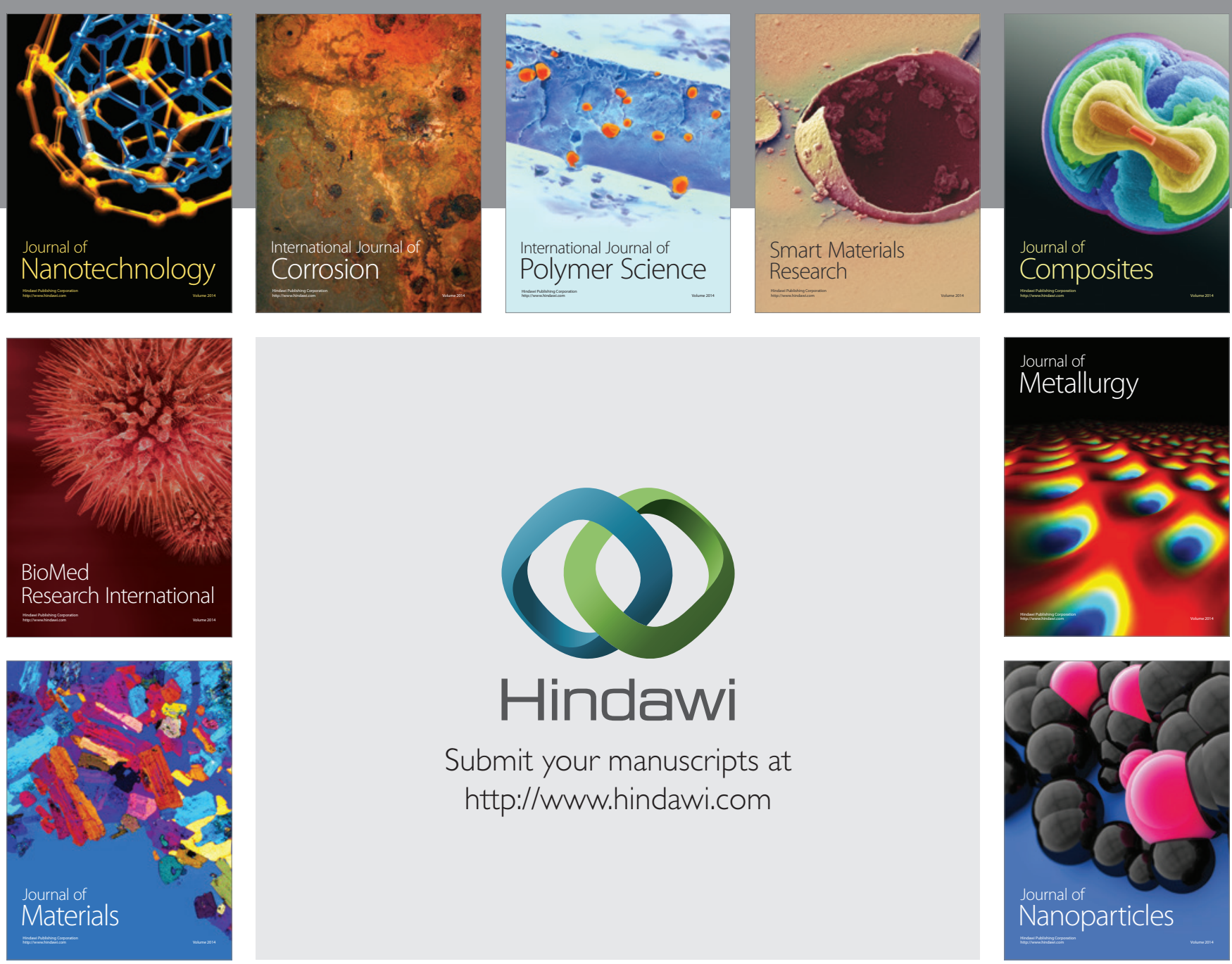

Submit your manuscripts at http://www.hindawi.com
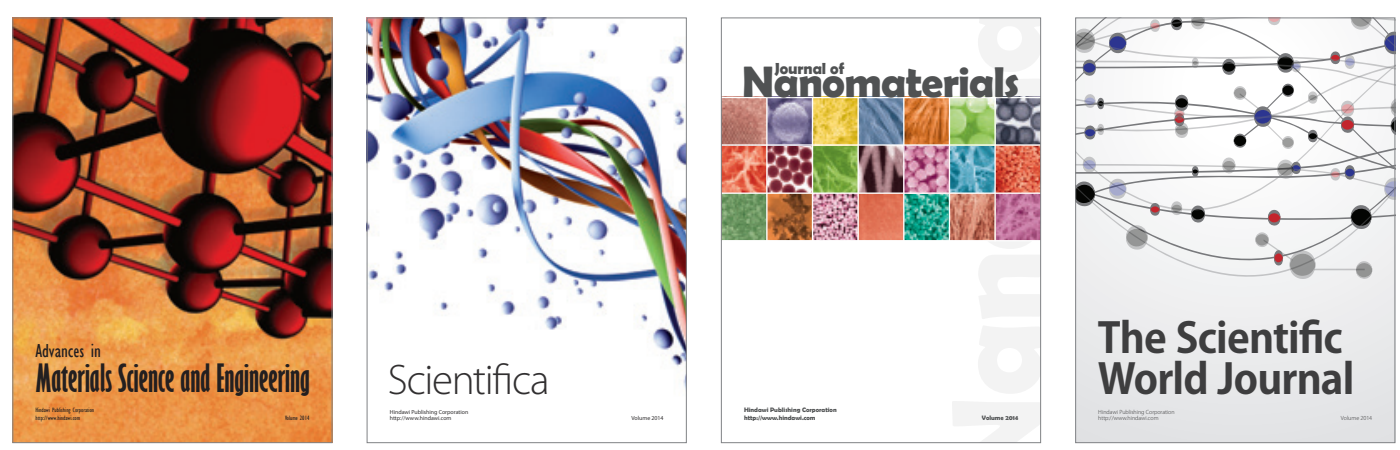

\section{The Scientific World Journal}
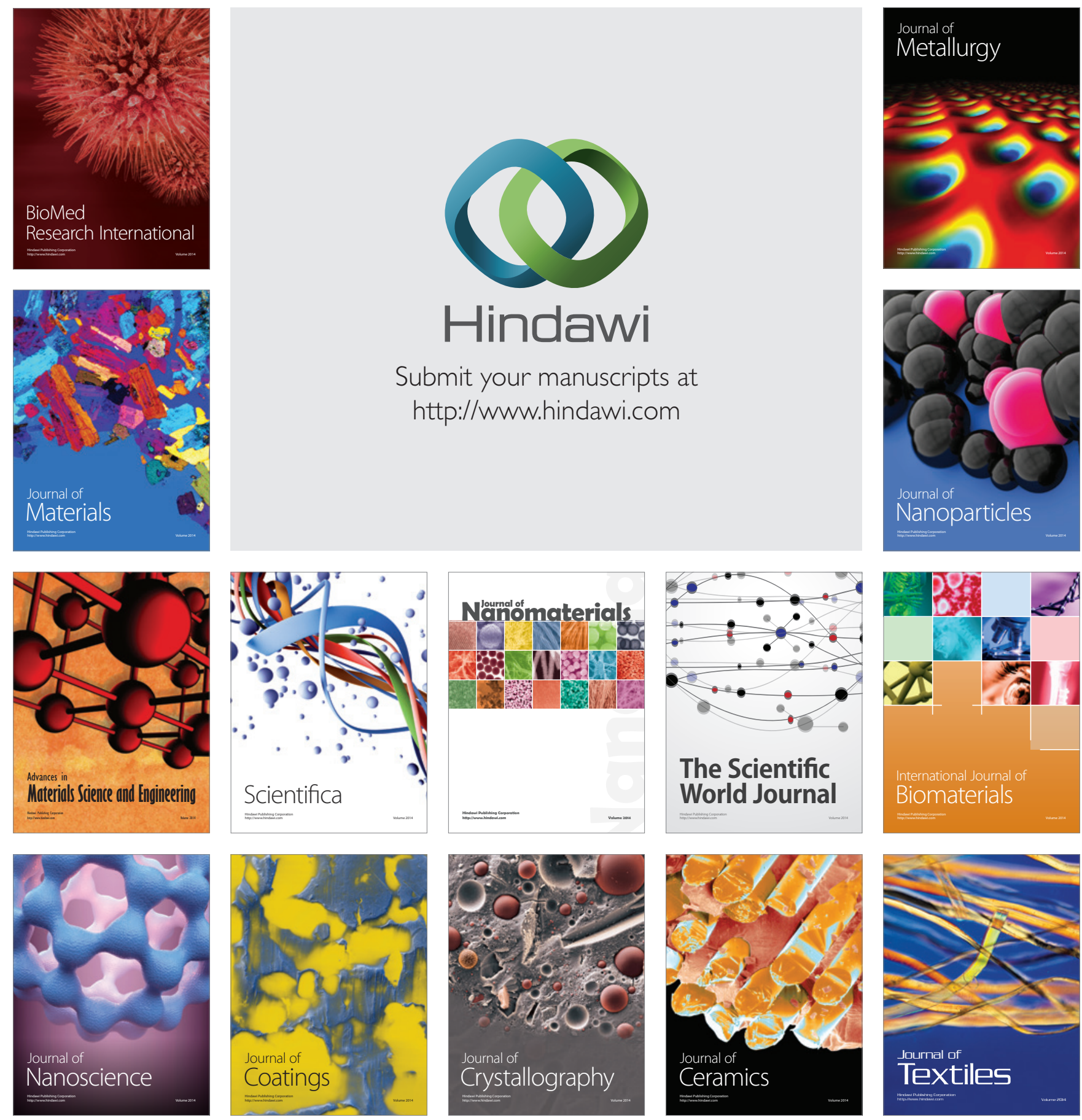